\title{
The Forestry Research Partnership: Developing the partnership
}

\author{
by George Bruemmer ${ }^{1}$
}

\section{ABSTRACT}

Initiated in 1999 by Tembec Inc., the Ontario Ministry of Natural Resources, Natural Resources Canada, and housed at the Canadian Ecology Centre, the Canadian Ecology Centre - Forestry Research Partnership (referred to as the CECFRP) quickly evolved into an effective and successful catalyst, facilitator, and funding source for integrated forest research and development in Ontario. This paper highlights the development of the partnership and serves as an introduction to a collection of papers that highlight some of the forest science and research projects undertaken by the CECFRP over 7 years.

Key words: government-industry partnerships, science to operations continuum, enhanced forest productivity, research implementation

\section{RÉSUMÉ}

Mis en place en 1999 par Tembec Inc., le Ministère des Richesses naturelles de l'Ontario et Ressources naturelles Canada au Centre écologique du Canada, le Centre écologique du Canada - Partenariat pour la recherche forestière (désigné par CEC-PRF) sest rapidement développé en un catalyseur efficace et fructueux, un animateur de formation et une source intégrée de financement de la recherche forestière et du développement en Ontario. Cet article souligne le développement du partenariat et sert d'introduction à un recueil d'articles qui met en relief certains projets portant sur les sciences forestières et la recherche entrepris par le CEC-PRF au cours d'une période de 7 ans.

Mots clés : partenariat gouvernement-industrie, continuum entre les sciences et les opérations, productivité forestière accrue, implantation de la recherche

\section{Introduction}

The Canadian Ecology Centre - Forestry Research Partnership (CEC-FRP) was initiated in 1999 by Tembec Inc, the Ontario Ministry of Natural Resources (OMNR), and Natural Resources Canada (NRCan). Recognized as a strong positive force for integrated forestry research and development in Ontario, the CEC-FRP has also become a successful partnership model for research in Canada. This paper, and the companion papers featured in this issue of The Forestry Chronicle, examine the short history of the CEC-FRP with a view to describing what has made it successful and why, both to document and market its approach and to outline next steps.

The CEC-FRP established its base of operations at the Canadian Ecology Centre (CEC) in Mattawa, Ontario. Its 3 primary partners agreed to support the partnership for a period of 5 years, subject to renewal after a review of performance. The first strategic plan was approved on April 30, 2000 (CEC-FRP 2000), and its first 5-year report was released October 31, 2005 (CEC-FRP 2005). In 2008, despite a massive downturn in the economic performance of the forest sector, including that of Tembec, the partners have continued to support the CEC-FRP, allowing it to maintain a strong program.

The activities of the CEC-FRP have been managed by a small dedicated team of motivated people drawn from all 3 of its partner organizations. The CEC-FRP has prospered as a direct consequence of strong support from senior management of all 3 partners, as well as from the engagement, enthu- siasm, and expertise of scientists and forest managers alike, across Ontario. In return, the CEC-FRP has provided its partners-and Ontario-a unique forest science service that the individual partners could not have delivered on their own.

The CEC-FRP has developed a solid reputation for getting things done, for being cost-effective, and for working openly, honestly, and pro-actively with an array of collaborators across Canada. Its innovative private/public partnership structure, coupled with ready access to the significant scientific, intellectual, and financial resources of its primary partners, have provided all the elements required to deliver a focused, innovative and dynamic science program that is poised to continue to add value into the future.

\section{The Policy Context}

Canada is a signatory to all major global instruments concerning temperate forests. These include, among others, the Convention on Biological Diversity (CBD; 1992), the Montreal Process (1994), the Santiago Declaration (1995), and the Kyoto Protocol (1997). To comply with these global instruments, the province of Ontario adopted an ecosystem-based management approach in the early 1990s and implemented new legislation and policy to support it. OMNR's forest management objectives changed from predicting and controlling harvest under the Crown Timber Act to maintaining forest structure, composition, and function under the new Crown Forest Sustainability Act (Statutes of Ontario 1995).

$\overline{{ }^{1} \text { Executive Director, Canadian Wood Fibre Centre, Natural Resources Canada, Ottawa, Ontario K1A 0E4. E-mail: GBruemme@NRCan.gc.ca }}$ 
In Canada, both the provincial and federal governments have powers with respect to aspects of managing forested lands. The provincial governments, however, are owners of approximately $90 \%$ of forested lands in Canada, and have sole responsibility for regulating forest management on Crown forests. All of the research work of the CEC-FRP has occurred on Crown lands in Ontario, and consequently has been carried out in accordance with the Ontario regulatory environment, while influenced by the broader national policy framework.

In response to growing domestic and international pressure to increase protected areas in Canada, in the 1990s the province of Ontario began a comprehensive land-use planning exercise on public forested lands, known as Ontario's Living Legacy (or Lands for Life). This exercise had 4 key objectives:

- To complete Ontario's system of parks and protected areas (target: $12 \%$ of public lands),

- To recognize the land-use needs of the resource-based tourism sector and to set the stage for implementation of the Resource-based Tourism Policy,

- To provide the forest, mining, and other resource industries with a greater degree of certainty regarding availability of land and resources, and

- To enhance angling, hunting, and other Crown land recreation opportunities (OMNR 1999a).

The trilateral signing of the Ontario Forest Accord (OMNR 1999b) by representatives of the province, the forest industry, and the environmental community, formally endorsed the Lands for Life process and its outcomes. The Accord in effect supported a substantial reduction to the commercial forest landbase when available wood supply was emerging as a limiting factor to industrial productivity. To offset that reduction, it also supported sound forest management practices that would increase the average growth and yield from Ontario's forests. Perhaps most importantly, it signalled the willingness of traditional adversaries to work together to achieve what in some ways appeared to be the mutually exclusive objectives of the Lands for Life initiative, and in doing so to bring stability and predictability to forest land use in Ontario.

Clause 5 in particular of the Accord established the context for the CEC-FRP:

Accord Clause 5: Develop an Ontario forest science partnership in order to:

1. Develop and test a range of intensive forest management (IFM) practices

2. Assess the impacts of IFM on increased forest growth and yield

3. Assess the environmental impacts of IFM

4. Direct science activities in support of Ontarios forest management planning requirements under the Timber Class Environmental Assessment and Crown Forest Sustainability Act

\section{The Mission and Objectives of the Forestry Research Partnership}

In its short history, the CEC-FRP has organized and managed approximately 140 forest science projects, all in one form or another supporting the mission of the CEC-FRP: to identify, develop and implement ecologically sustainable and scientifically defensible leading edge forestry practices required to maintain and enhance an economically viable supply of quality fibre to Tembec mills, and to the communities those mills support, over the long term.

Three additional desired outcomes were articulated in the strategic plan (CEC-FRP 2000), intended to be used to measure the success and value of the partnership. These were:

1. Certainty around current and future wood supply, with the underlying objective being to facilitate corporate capital decision-making. This will require:

- Accurate continuous inventories of the existing forest resource;

- Models whose inputs are precisely calibrated, and whose outputs accurately forecast allowable cut, ecological sustainability, community stability and economic viability. These models will require constant ongoing refinement to reflect the inherent complexity of each element, and the potential volatility over time that accompanies their interaction.

2. Shareholder and taxpayer value.

- Research and development (R\&D) projects in forest renewal must demonstrate a positive contribution toward meeting forecasted corporate fibre supply requirements.

- $\mathrm{R} \& \mathrm{D}$ projects in forest harvesting and renewal must demonstrate a contribution to corporate cost reduction objectives.

- Corporate money is intended to lever other funding from government, industry partners, and other stakeholders as a means of maximizing corporate benefit at minimum cost.

- $\mathrm{R} \& \mathrm{D}$ projects must be developed in the context of provincial and federal policy.

- All projects must promote a progressive and positive corporate image for all the partners involved.

3. An effective science partnership that promotes good science, not only in Ontario, but across the country.

- Enlightened forest policy, sound forest management planning and useful operational tools are a natural result of a rigorous scientific approach in which many partners participate.

- Credible and defensible science will promote public acceptance and increase fibre growth at the same time.

- The development and introduction of proven innovative forest technologies are a cornerstone of future industry development.

Finally, the CEC-FRP established the "10/10" goal as the cornerstone of its research program. This objective proposed to identify technology and techniques to allow Tembec to increase the annual allowable cut (AAC) on its license areas in Ontario by $10 \%$ within 10 years. The 10/10 target was to be achieved in the context of ecological sustainability, reduced operational costs, improved fibre use, and enhanced future fibre quality.

\section{The Partners and Their Roles and Responsibilities}

The principal partners of the CEC-FRP are Tembec, the Ontario Ministry of Natural Resources, Natural Resources Canada and the Canadian Ecology Centre. The home of the CEC-FRP is the CEC in Samuel de Champlain Park near Mattawa. Along with a stellar venue, the CEC is the platform for many CEC-FRP activities. As well, its staff provides administrative and logistical support to the 3 principal partners. 
Tembec, the lead partner, is a large international forest company with a significant presence in 5 provinces in Canada as well as France. Tembec has a strong corporate culture of support for research and innovation, with a long and successful research and development history, particularly in manufacturing. The policy context described earlier provided the incentive for the company to develop a much stronger presence in forestry research and development as well.

Tembec's contributions were vital to the establishment of the partnership and in the first 5-year period included:

- A dedicated full-time manager to coordinate FRP activities through its start-up phase,

- Access to company-licensed landbases on which to implement forest science projects,

- Full participation in and contribution to other research and development initiatives and partnerships across Ontario and Canada,

- Senior management influence on the forest industry in support of forestry research and development, and

- Funding.

Ontario's provincial government, represented by OMNR, owns most forested lands in Ontario. OMNR's mandate includes provincial land use, promoting and regulating resource interests, and ensuring that lands and waters under the jurisdiction of the provincial government are used in the best interests of the people of Ontario and in accordance with the statutes it administers. OMNR shares the responsibility of managing approximately 21 million hectares of commercial forests with forest products companies or groups of companies and communities through sustainable forest licences (SFLs). The licenses that have been granted to Tembec give them the right to harvest all tree species and to carry out renewal and maintenance activities within the licensed areas on behalf of the province. ${ }^{2}$

OMNR's contributions were also vital to the establishment of the partnership and consist of:

- Strong scientific leadership and research support,

- Transfer support at all levels, and

- Policy and program support.

Natural Resources Canada specializes in the sustainable development and use of Canada's natural resources including: energy, minerals and metals, forests and earth sciences. A Memorandum of Understanding (MOU) between NRCan and OMNR promotes the delivery of efficient, effective, and collaborative forest science in Ontario. The participation of the 2 governments in the CEC-FRP is covered by this agreement. Contributions by NRCan were also critical to the partnership, and included:

- Science support, research and transfer at all levels, closely coordinated with the activities of OMNR,

- National perspectives and linkages, and

- Access to federal program funding.

The combination of funding from Tembec and scientists and technical support from OMNR and NRCan has proven very successful in garnering funding from other sources and in attracting intellectual participation from several Canadian universities.

\footnotetext{
${ }^{2}$ For example, http://www.mnr.gov.on.ca/MNR_E000473.pdf
}

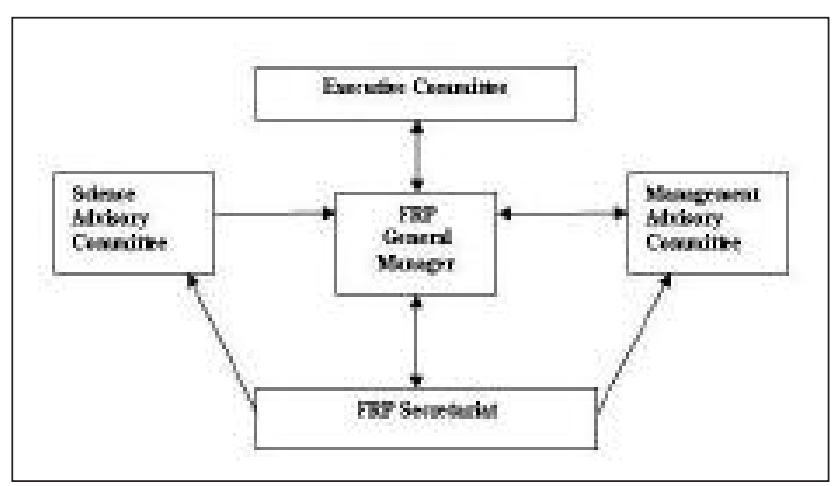

Fig. 1. Organizational structure of the Canadian Ecology Centre Forestry Research Partnership.

\section{Organizational Structure}

The CEC-FRP is managed by executive, management advisory, and science advisory committees, with the day-to-day operations run by a small group referred to as the secretariat (Fig. 1).

The executive committee is responsible for 5 key functions: (i) providing strategic direction to the CEC-FRP and setting high-level goals, (ii) reviewing and approving annual work plans to ensure that they mesh with individual partner organization priorities, (iii) annually reviewing accomplishments to ensure they are consistent with strategic directions, (iv) providing leadership in the development and pursuit of resource opportunities (capacity and capability, money, equipment, facilities, etc.) to support the partnership in delivery of science needs that address partner objectives, and (v) pursuing policy acceptance for innovation and science emerging from the partnership. The executive committee includes the vice-president of Tembec's Forest Resource Management Group, the CEC-FRP manager, the directors of OMNR's research and science branches, the NRCan-CFS director general and director of science programs. This group meets biannually to finalize budgets and approve priorities recommended by the management advisory committee.

The primary responsibilities of the management advisory committee include: (i) communicating and integrating CECFRP activities with their respective parent organizations, (ii) recommending strategic direction for the CEC-FRP that links with the strategic directions of individual partner members for presentation to the executive committee, (ii) developing an annual work plan for presentation to the executive committee and implementing the plan, (iv) coordinating inter-organizational collaboration, (v) conducting an annual review of the partnership and recommending direction, scope, context and priorities for the partnership to the executive committee, (vi) ensuring application of science knowledge and products emerging from projects by coordinating extension efforts for the partnership, and (vii) supporting core teams as required. The management advisory committee is chaired by the CEC-FRP manager, and comprises OMNR's science business coordinator, regional coordinators, program manager of OMNR's forest management planning section, NRCan-CFS managers, and an extension coordinator. The CEC-FRP manager chairs committee meetings held 4 times per year. 
The primary roles and responsibilities of the science advisory committee include: (i) ensuring excellence in science products and services and in the relevance and utility of project outputs, (ii) communicating and integrating CEC-FRP activities with their respective parent organizations, and (iii) ensuring application of science knowledge and products emerging from CEC-FRP projects by actively supporting extension efforts for the partnership. The science advisory committee focuses on ensuring that all relevant products are applied in a timely manner. This committee is chaired by OMNR's science business coordinator and includes Tembec's regional foresters and silvicultural specialists, OMNR scientists and regional specialists, NRCan-CFS research scientists and extension coordinators, and private consultants.

The secretariat comprises individuals tasked with managing the day-to-day business of the partnership. The secretariat and general manager interact with the science advisory, management, and executive committees to ensure that the partnership functions efficiently.

\section{The Program and its Results}

The CEC-FRP chose an adaptive management approach (see Fig. 2; for details see Bell et al. 2008, this issue) with a very specific goal: increase available wood volume by $10 \%$ over 10 years-referred as the 10/10 goal. Short-, medium-, and longterm objectives were set and project selection criteria were determined before the program was initiated. Phase 1 (above the dashed line) addressed short- and medium-term objectives. Phase II (below the dashed line) addressed longer-term objectives.

Most CEC-FRP efforts between 2000 and 2005 focused on Phase I, and involved building a solid foundation of knowledge and information from which to conduct a series of sensi- tivity analyses to determine whether the longer-term 10/10 goal was plausible and, more importantly, sustainable. Phase 2 , from 2005 forward continues that process, but with a greater emphasis on implementation, monitoring, and evaluation.

Many projects, on several different themes, were initiated in parallel at the outset of the program. In a determined effort to avoid re-inventing the wheel, initiators of these projects looked to the past for data from literature reviews, re-measurements of old trials, or existing work underway elsewhere. Efforts were made to standardize all data collected to ensure compatibility among projects and to facilitate data-sharing. The common purpose in every case was to contribute credible information to the objective of a sustainable increase in wood supply of $10 \%$ in 10 years, with "sustainable" in this context meaning more wood produced in concert with good management of multiple forest values.

Model-based, landscape-level sensitivity analyses (simulations of various management options) were needed to determine whether or not the 10/10 wood-supply goal was realistic and to identify knowledge gaps with respect to growth and yield, biodiversity, economics, social issues, protection, education, and training. Several key projects were undertaken, using the provincial aspatial sustainable forest management model (SFMM) and the spatial Patchworks models to evaluate scenarios (details in Rouillard and Moore 2008, this issue).

For the Tembec management units on which extensive modelling was conducted, the analyses indicated that the forecasted supply declines over time projected in forest management plans could be arrested by implementing an intensive silviculture program on a limited proportion of the forest landbase. This intensive program, strategically applied, would produce more fibre without negative effects on other forest values and without significant increase to forest renewal costs.

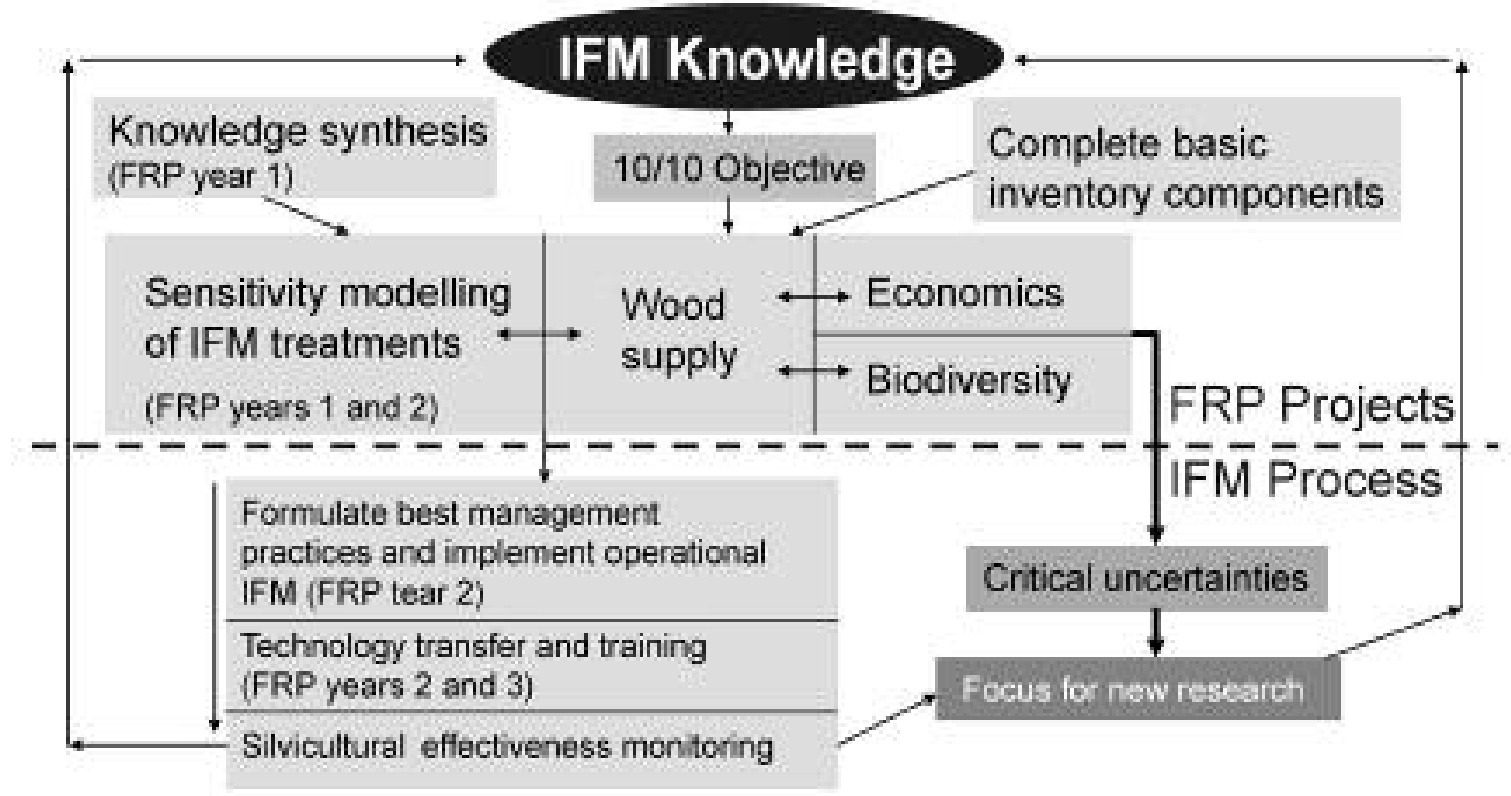

Fig. 2. Adaptive management framework within which to implement intensive forest management (IFM) as adopted by the Canadian Ecology Centre - Forestry Research Partnership (adapted from CEC-FRP 2000). 
Perhaps the most significant, and valuable result of the CEC-FRP work to date has been an improved understanding of the interdependent relationships between wood supply, forest ecosystems, economic performance, and forest management decisions. The tools produced, while still incomplete and imperfect, have provided a useful-and in many respects unique-vehicle with which to evaluate the effects of the trade-offs inherent in sustainable forest management in its broadest sense.

The CEC-FRP has developed an exciting, effective, and widely recognized extension and technology transfer program (details in Smith et al. 2008, this issue). Extension products include a Web site, technical notes, over 60 workshops and field trips, continuing education and professional development courses, as well as published papers. Extension efforts, using a variety of different media, have been directed to numerous forest sector audiences from the logger to the academic and from the field forester/technician to the executive policymaker. The partners have also worked closely with the CEC to deliver relevant forest science messages to over 5000 visiting students and their teachers annually.

More details about the CEC-FRP program, projects, and next steps are provided in the subsequent papers that form part of this special edition of The Forestry Chronicle.

\section{Concluding Remarks}

The success the CEC-FRP has enjoyed to this point can be attributed to 3 main factors:

- It provided a strong focused response to a pressing policy question at an opportune time, in this case the forest productivity component of the Lands for Life initiative in Ontario. The clear focus on enhanced wood supply is as pertinent and pressing now as when the CEC-FRP was initiated.

- The science products generated by the CEC-FRP have always been of high quality. Much of the science work of the CEC-FRP was undertaken by provincial and federal government scientists; some was also completed by university researchers. In every case, strong scientific rigour, and an emphasis on scientific excellence, has been maintained. Equally as important, the science products of the CEC-FRP have been relentlessly and effectively transferred to an array of audiences. As a result, the science has had a direct influence on policy and practice.
- Working together, the primary partners were able to create a unique program that none could have delivered on their own. The financial, intellectual, and management resources that each partner brought to the CEC-FRP enabled a comprehensive, well-leveraged response evident in the CEC-FRP program. The CEC-FRP has been a good investment by its partners, both individually and collectively, and, most importantly, its scientists, field practitioners, and senior managers agree.

\section{Acknowledgements}

All CEC-FRP members extend a thank you to Frank Dottorii (former president and CEO of Tembec) for envisioning and supporting the partnership. I also thank the many members of executive, management advisory, and science advisory committees and the secretariat whom I know have spent many hours working to ensure the success of the partnership; the numerous researchers who designed and implemented close to 150 projects, and the members of the core teams who worked to ensure the results are implemented.

\section{References}

Bell, F.W., J.A. Baker, G. Bruemmer, J. Pineau and A. Stinson. 2008. The Canadian Ecology Centre - Forestry Research Partnership: Implementing a research strategy based on an active adaptive management approach. For. Chron. 84(5): 666-677.

[CEC-FRP] Canadian Ecology Centre - Forestry Research Partnership. 2000. The Canadian Ecology Centre - Forestry Research Partnership strategic plan. Can. Ecol. Cent., For. Res. Partnership, Mattawa, ON. 33 p.

2005. Forestry Research Partnership 5-year report (20002005). Can. Ecol. Cent., For. Res. Partner., Mattawa, ON. 24 p.

[OMNR] Ontario Ministry of Natural Resources. 1999a. Ontario's Living Legacy land use strategy. Ont. Min. Nat. Resour., Toronto, ON. 136 p.

1999b. Ontario Forest Accord and Living Legacy Trust [online]. Ont. Min. Nat. Resour., Toronto, ON. Available at http:// www.mnr.gov.on.ca/MNR_E001782.pdf [Accessed May 2008].

Rouillard, D. and T. Moore. 2008. Patching together the future of forest modelling: Implementation of Patchworks in the 2009 Romeo Malette forest management plan. For. Chron. 84(5): 718-730.

Smith, G.K.M., J.F. Pineau and F.W. Bell. 2008. Knowledge transfer and extension in the Canadian Ecology Centre - Forestry Research Partnership: From awareness to uptake. For. Chron. 84(5): 748-755. Statutes of Ontario. 1995. Crown Forest Sustainability Act, revised. R.S.O. 1998. Chapter 25 and Ontario Regulation 167/95. 